\title{
A scientific approach to navigating the academic job market
}

\author{
Sofia Beas ${ }^{1,2,4 凶}$ and Kirstie A. Cummings $\mathbb{D}^{3,2,4 凶}$ \\ This is a U.S. government work and not under copyright protection in the U.S.; foreign copyright protection may apply 2021
}

Neuropsychopharmacology (2022) 47:621-627; https://doi.org/10.1038/s41386-021-01225-w

After consulting with your mentors, you have decided to go on the job market this year [1-3]. Congratulations! This is a huge milestone. One that you have worked hard for since starting your scientific career. Now, you are probably asking the following: How do I go about it? This commentary aims to provide guidance for approaching the academic job search process and offer resources to help candidates start on the path towards obtaining their dream job. Importantly, we want to emphasize that the job search process is one of the most important scientific endeavors a candidate can undertake. As such, the process requires a significant commitment of time and effort [4].

\section{NAVIGATING THE ACADEMIC JOB MARKET}

The job search process can be divided broadly into four stages: 1 . Preparing, searching, and applying for positions; 2. Pre-interviews; 3. Interviews; and 4. Post-interview processes. In Table 1, we provide candidates with a breakdown of each stage of the job search process. We include short descriptions, the estimated timeline, recommendations drawn from our experiences on the 2020-2021 job market, and resources we found to be helpful. In the era of COVID-19, a vast majority of institutions turned to virtual formats to conduct interviews. While virtual interviews offer some benefits (e.g., no travel), challenges can also arise [5]. Therefore, in Table 1, we also provide additional considerations for the "virtual" job search. Note that the advice and resources cited in Table 1 are not exhaustive but should serve as a solid foundation to get candidates started. In addition, we focus on searching for a position at an R1 institution. Approaches will vary for small liberal arts colleges, which place more weight on teaching and conducting research with undergraduates (For more information, see Table 1 "Different types of academic jobs" resource).

\section{APPROACH THE JOB MARKET LIKE A SCIENTIFIC PROJECT}

To prepare for the job search process, we recommend that candidates put their scientific mind and skills to work and ask: If this is my most important scientific endeavor to date, what would I do to ensure its success? Below, we suggest some recommendations.

1. Make it a priority and plan ahead. All the steps outlined here require ample time and effort. Thus, we recommend that applicants start preparing and planning for the process some months ahead of the application deadlines. Note that many job applications open in the summer and have rolling or hard deadlines in the Fall (Current events like the COVID19 pandemic could influence application deadlines). We recommend applying early and broadly. The early bird gets the worm!

2. Do the research. There are numerous resources available that outline the academic job search process (e.g., articles, books, webinars, social media platforms). Here, we provide a starting point (Table 1), but highly recommend that candidates use their scientific skills to identify additional resources. In addition, we also encourage applicants to seek advice from the experts, including those who have successfully navigated the job market recently as well as those who have served on hiring committees.

3. Prepare, strategize, and organize. Once candidates have done their research and identified job opportunities, we recommend they consider the following:

a. Availability of jobs. Consider location, job opportunities for significant others, and the prospects of whether the specific position will be academically and personally fulfilling $[2,6,7]$. With that said, we strongly recommend that candidates do not discount any opportunities since it is difficult to know the specifics of the job and whether it would be a good fit based on the advertisement.

b. Remaining organized. Use a spreadsheet to keep track of job advertisements, deadlines, and specific requirements for each job packet (i.e., statements, copies of publications, etc.). In addition, candidates should make plans for how each application will be tailored for each specific job posting with a particular focus on how the candidate 'fits' in the department and institution [2] (see 7 below).

c. Keeping track of reference letters. Candidates should keep their referees constantly updated by sharing their job spreadsheet (as suggested in $3 \mathrm{~b}$ ) and sending them information about job descriptions and deadlines soon after applying.

4. Seek "peer-review" from colleagues. Identify people who can provide honest feedback on application documents, interviewing skills, job talks, chalk talks, and any other part of the process.

5. Think critically. When it comes to subjective advice (e.g., this Commentary, peers, etc.), we recommend that candidates utilize several resources (colleagues, Google, Future PI

\footnotetext{
${ }^{1}$ Unit on the Neurobiology of Affective Memory, National Institute of Mental Health, Bethesda, MD, USA. ${ }^{2}$ Department of Neurobiology, University of Alabama at Birmingham, Birmingham, AL, USA. ${ }^{3}$ Nash Family Department of Neuroscience, Friedman Brain Institute, Icahn School of Medicine at Mount Sinai, New York, NY, USA. ${ }^{4}$ These authors contributed equally: Sofia Beas, Kirstie A. Cummings. ${ }^{凶}$ email: sbeas@uab.edu; kac3@uab.edu
} 

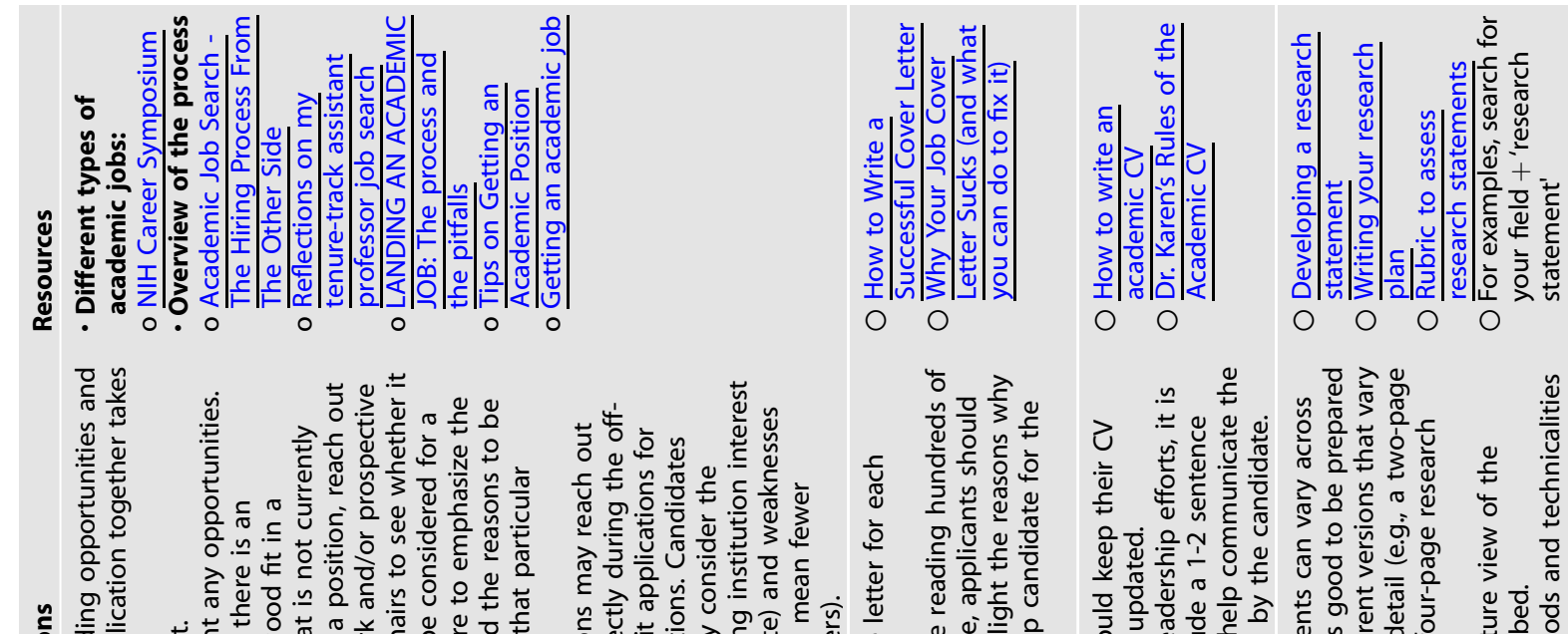

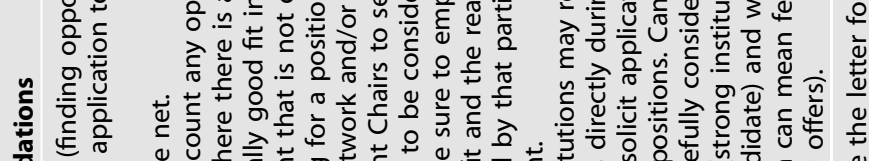

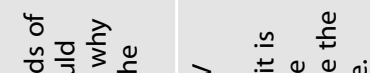

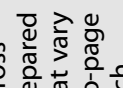

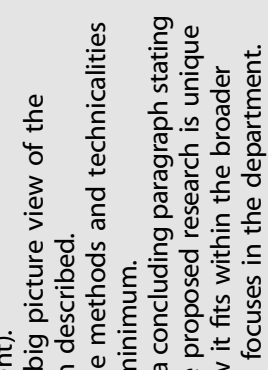

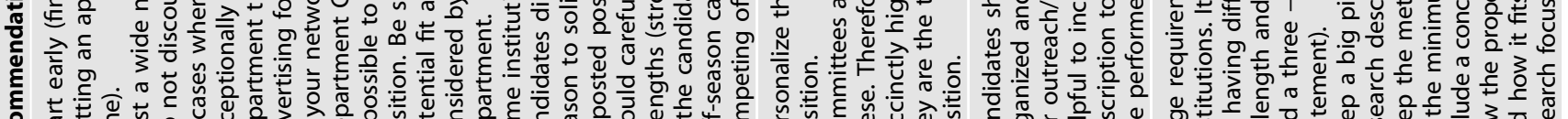

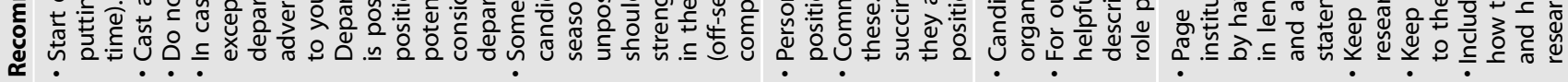
离

泀

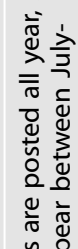

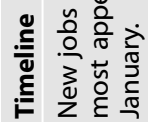

है

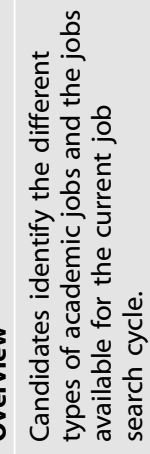

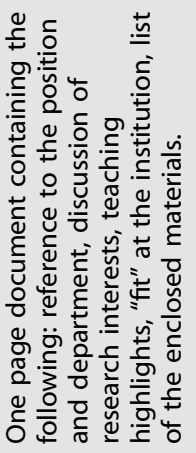

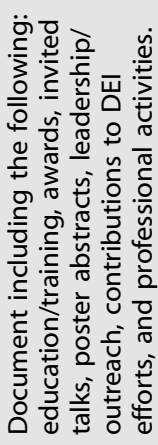

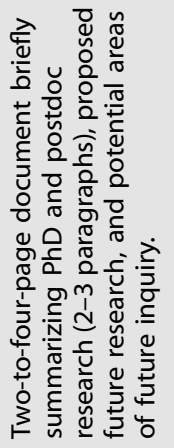

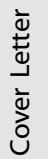

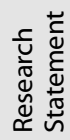

己

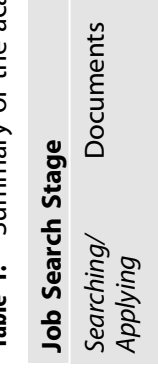



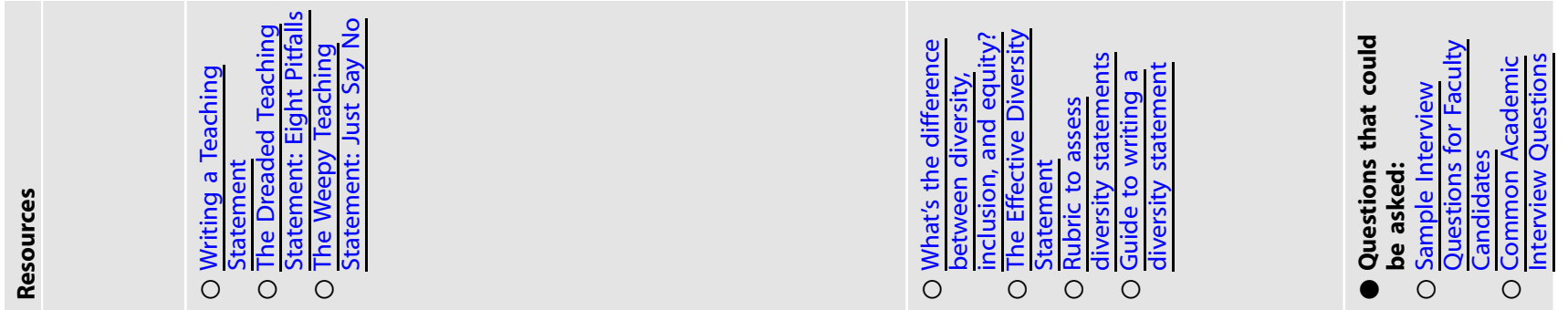

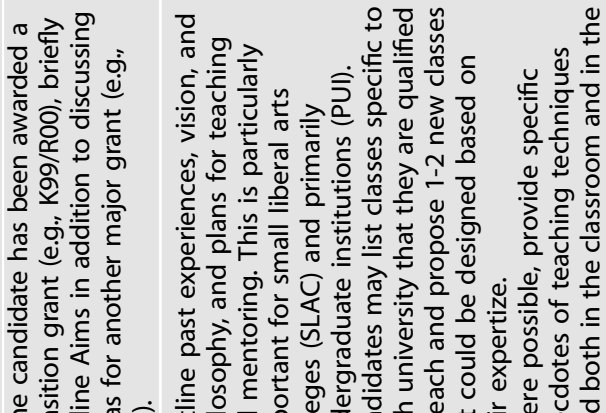

ह

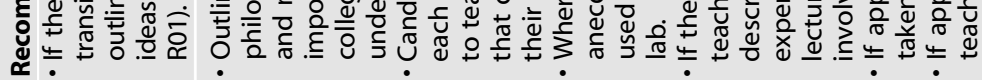



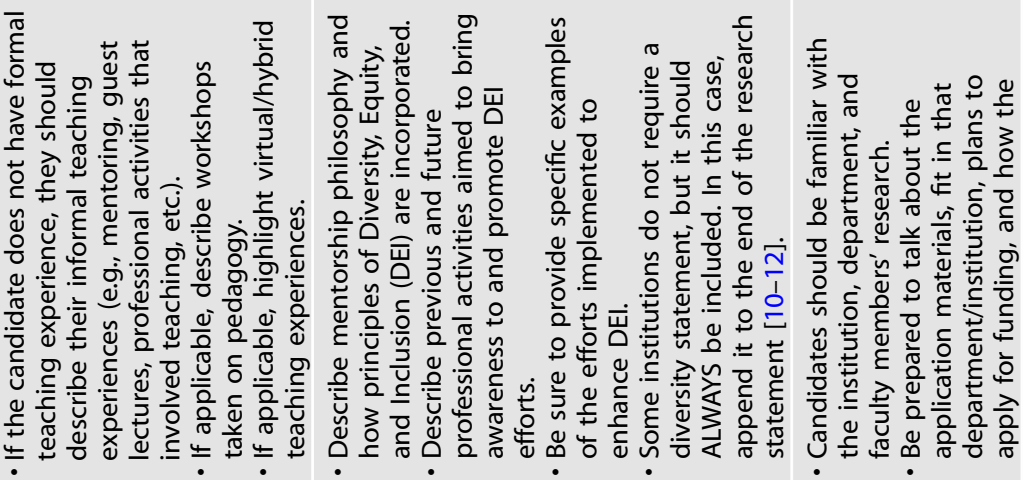

蒿

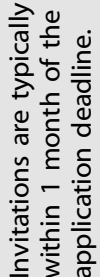
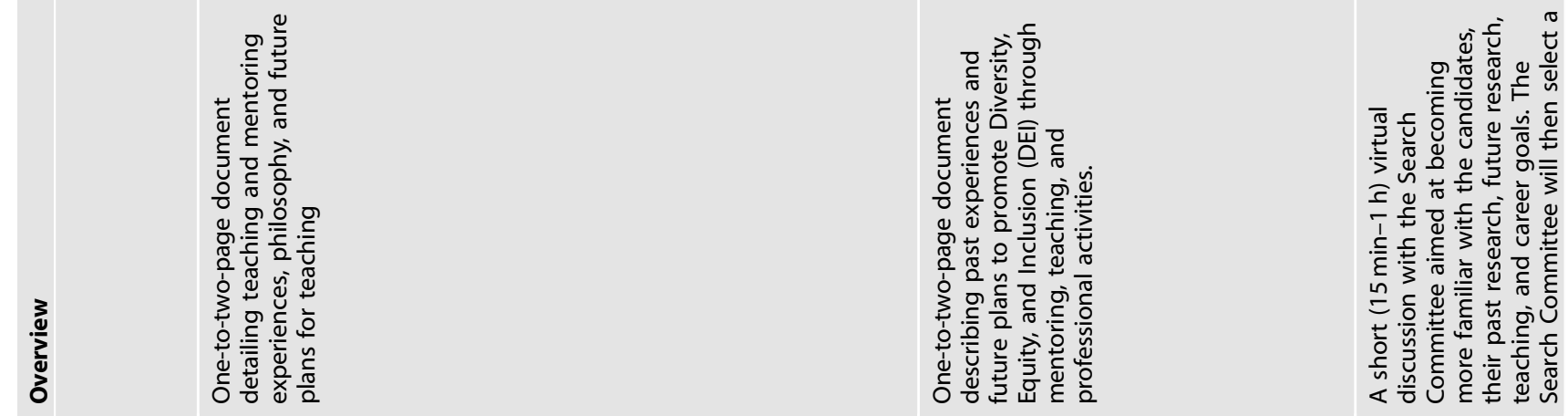

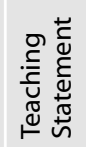

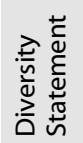

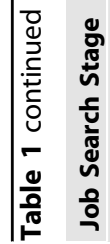

¿. 

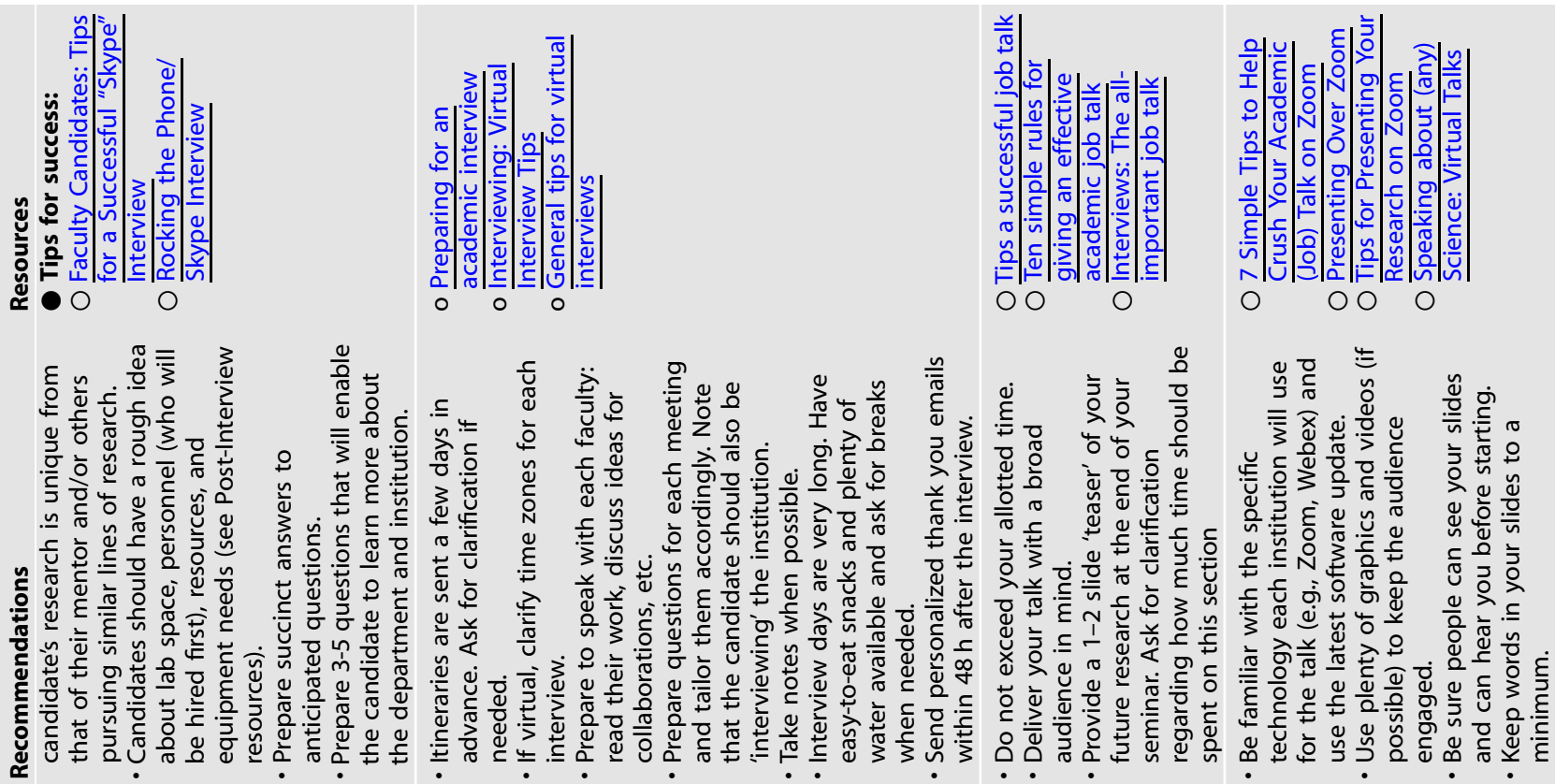

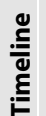

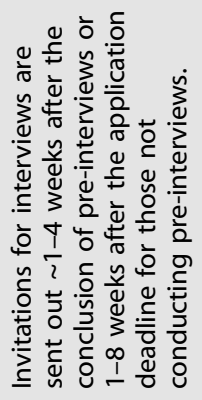

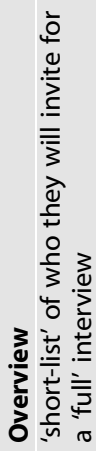
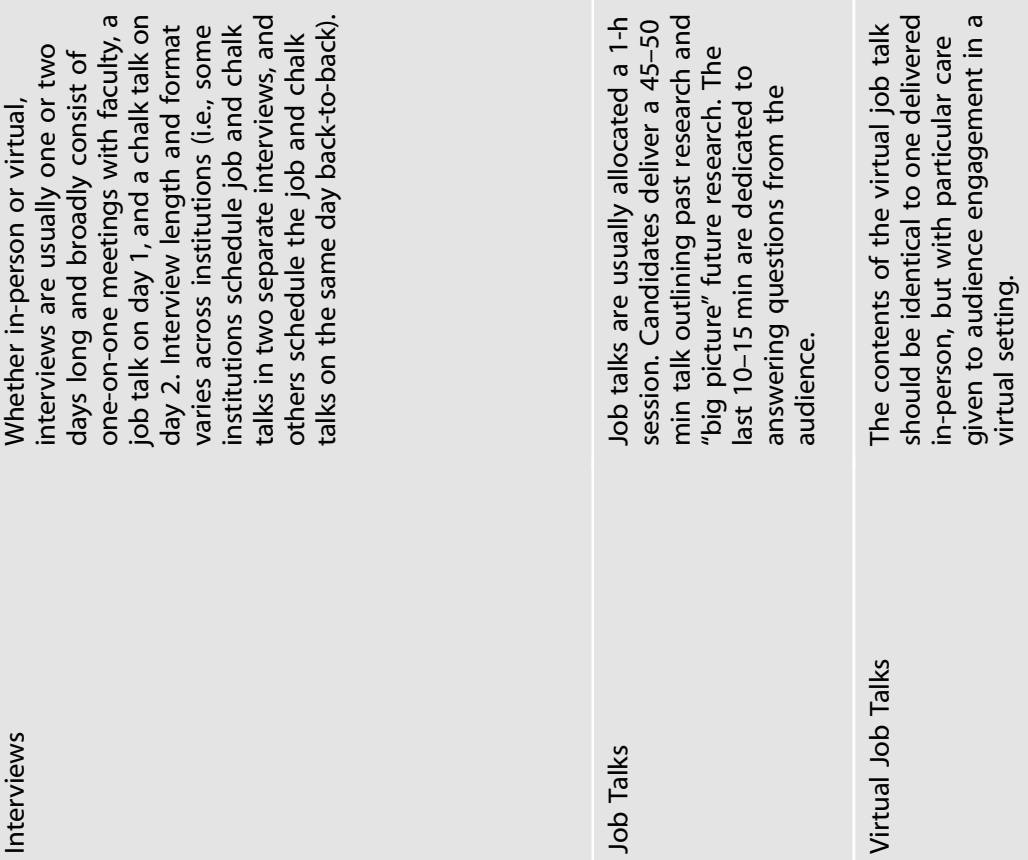

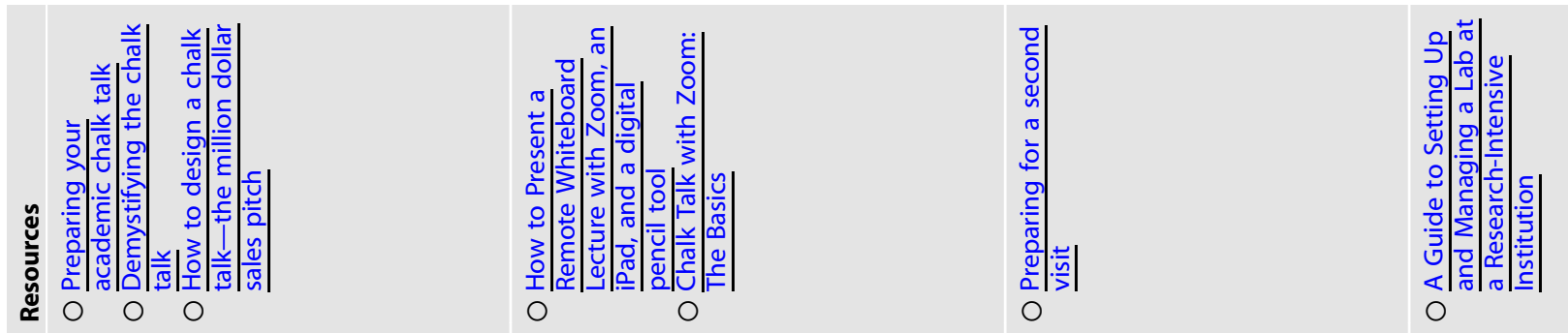

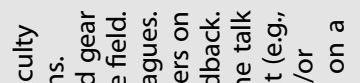

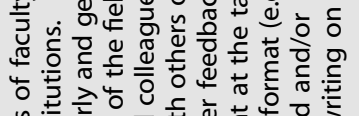

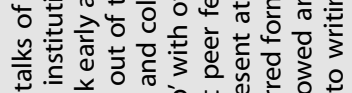

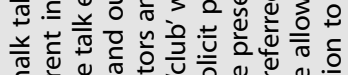

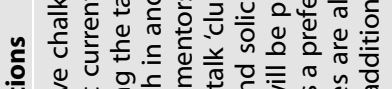

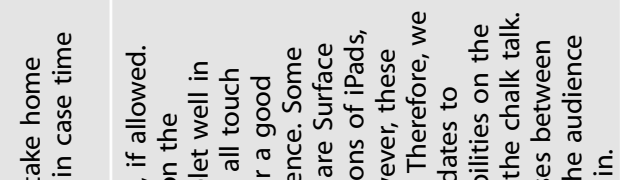

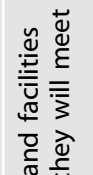

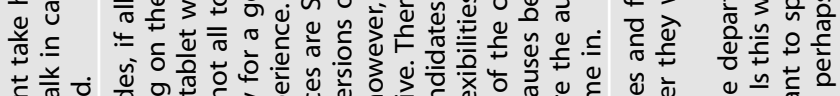

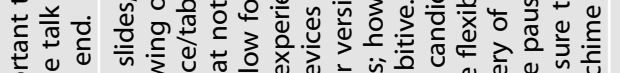

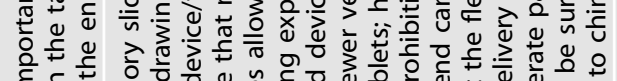

茎这

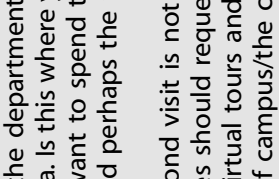

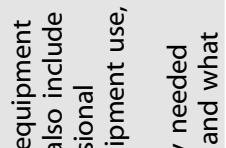

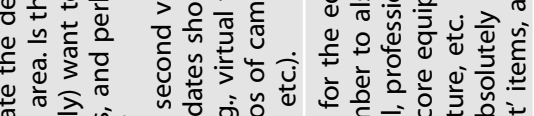

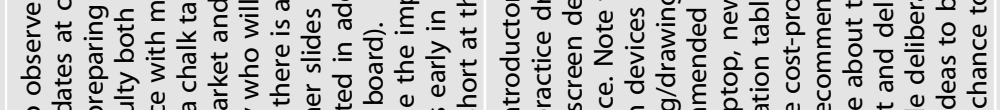

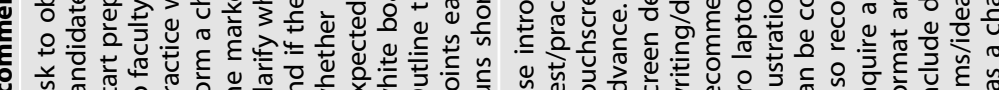

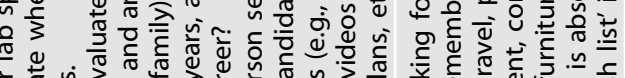

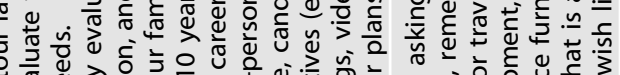

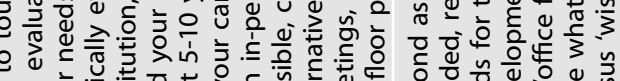

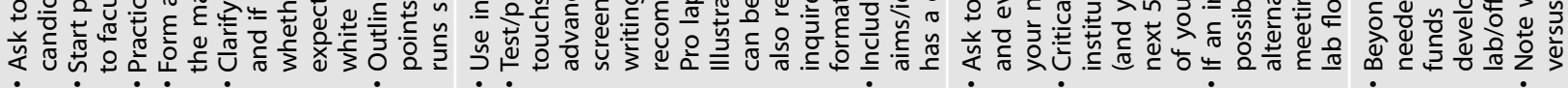

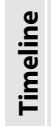

\begin{tabular}{|c|c|}
\hline 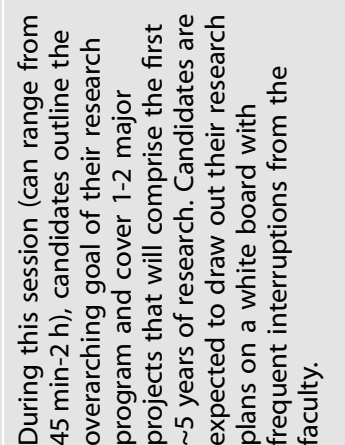 & 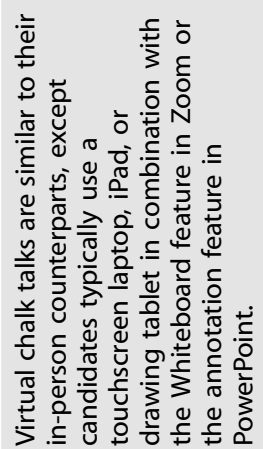 \\
\hline
\end{tabular}

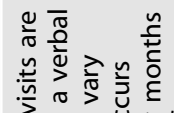

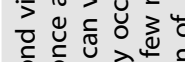

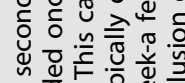

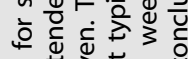

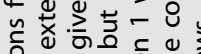

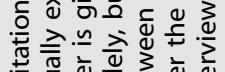

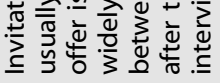

\begin{tabular}{|c|c|}
\hline 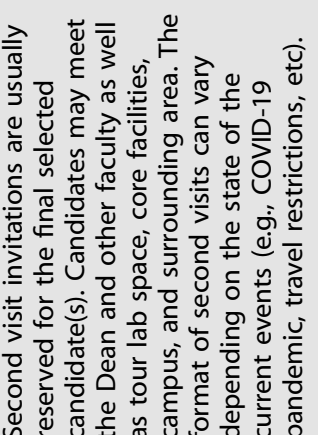 & 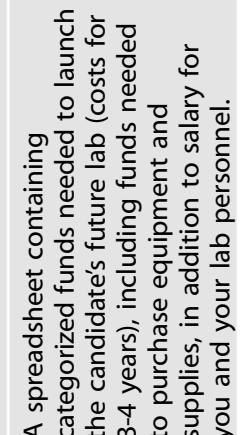 \\
\hline
\end{tabular}

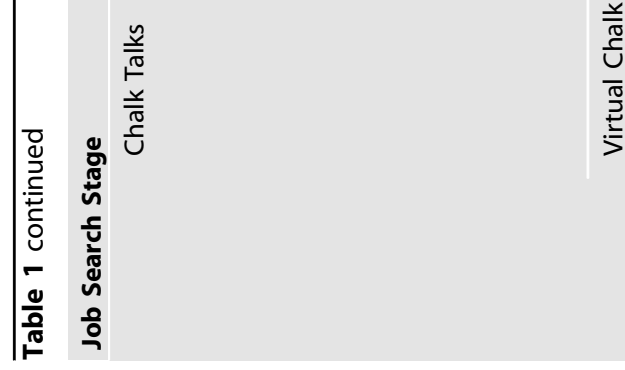

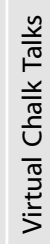

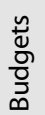

ț. 

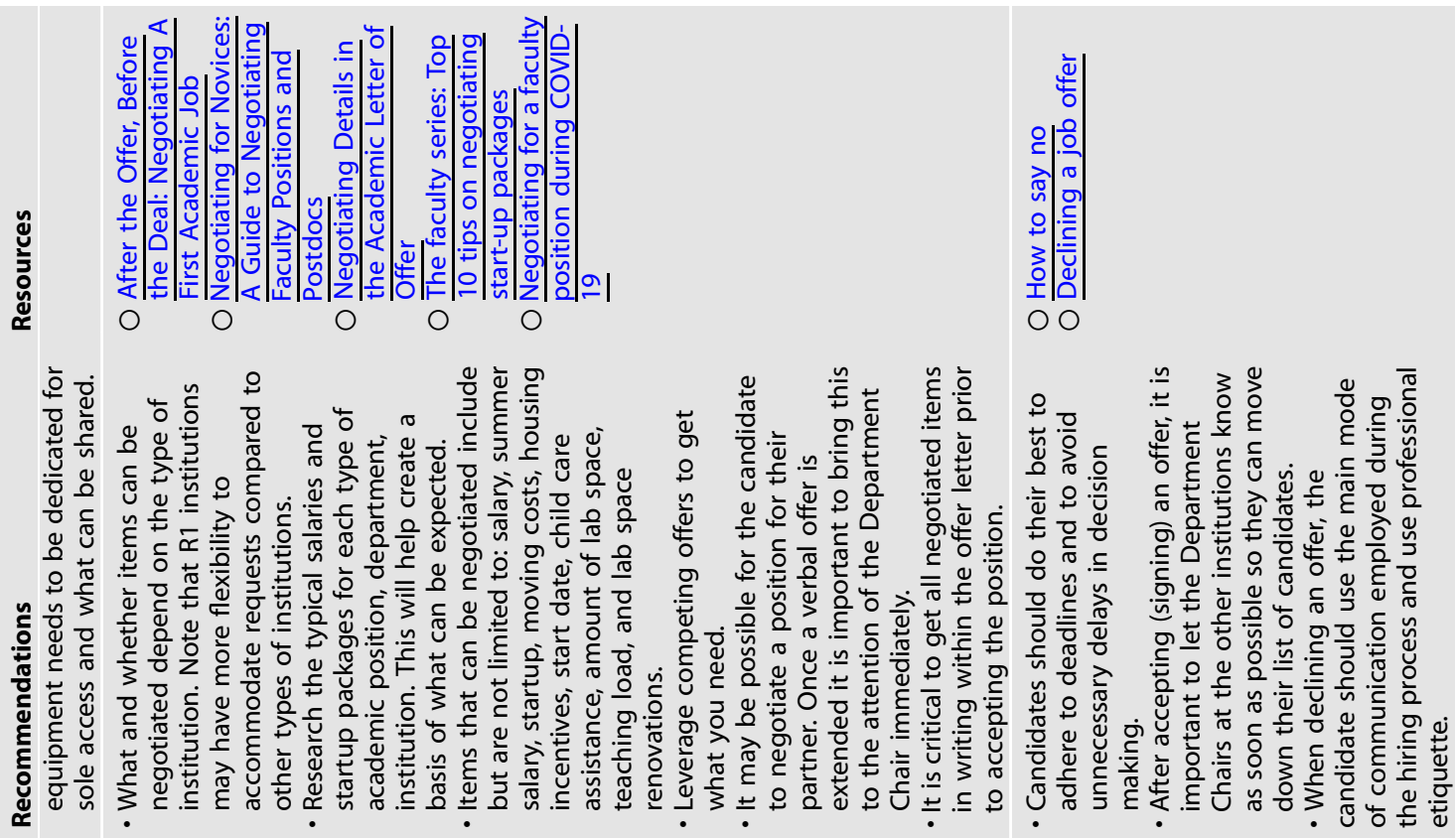

$\stackrel{\text { s. }}{\text { है }}$
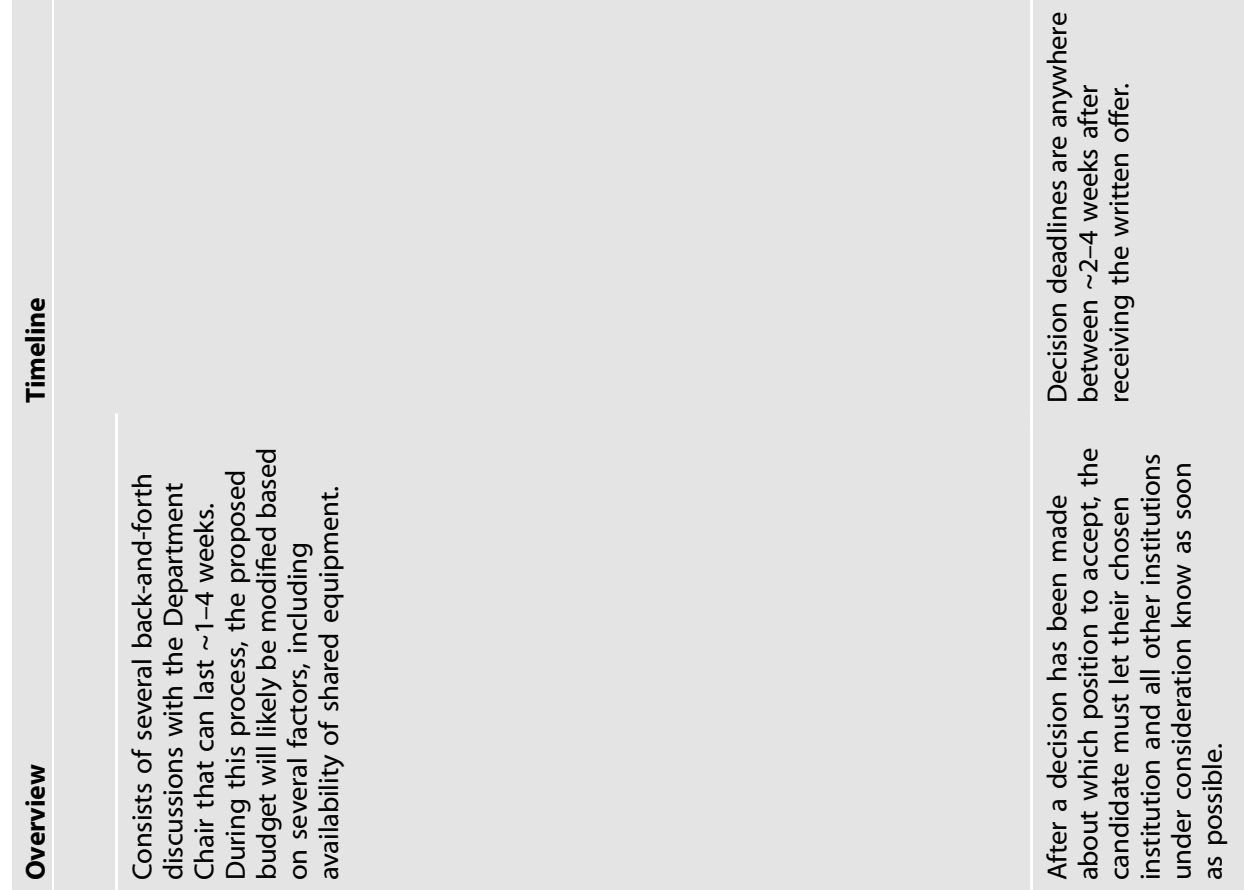

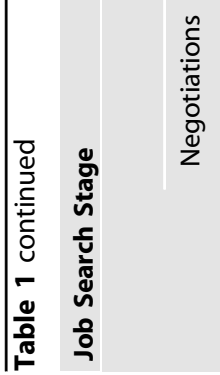

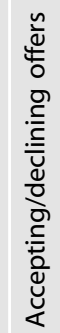


Slack, articles, books), to gather multiple lines of evidence for the advice, to be mindful of the source of the advice, to think critically about all the advice given, and to draw their own conclusions [8]. For example, advice from peers who recently secured a position may be more useful than advice from those who are less abreast of current practices. However, a good rule of thumb is that if multiple sources offer similar advice, it is most likely worth taking.

6. Be part of a scientific community. Form a support group of peers who are also on the job market to share advice, approaches, support, and celebrations. Future PI Slack also provides an anonymous group of peers on the job market that can support those embarking on the journey alone. In addition, it is beneficial to form a virtual or in-person job/ chalk talk "club" with other senior postdocs to practice with and receive feedback on delivering these talks.

7. Network. A significant contributor to the hiring decision is whether the candidate is a good ' $\mathrm{fit}$ ' and if it is clear that they will be successful in the department $[1,2,9]$. However, this information is usually not widely available. It is therefore critical to build connections through networking with colleagues to gain insights in that regard. Networking can be done both virtually and in person at meetings/courses, on social media (e.g., science Twitter), and through professional societies (e.g., Women in Learning). Candidates may also leverage the networks of previous and current mentors.

Being on the academic job market is undoubtedly a timeconsuming and stressful venture that requires much stamina and hard work [4]. However, it is also one of the most exciting and rewarding experiences for a junior scientist. As such, we strongly encourage candidates to enjoy the process, have fun with it, and view it as an excellent opportunity to meet, network, and discuss science with some of the brightest people in the world.

\section{REFERENCES}

1. Clement L, Dorman JB, McGee R. The Academic Career Readiness Assessment: clarifying hiring and training expectations for future biomedical life sciences faculty. LSE. 2020;19:ar22.

2. Pain E. "Maximize your chances of landing a faculty job." Science, 2013. https:// www.science.org/content/article/maximize-your-chances-landing-faculty-job. Accessed 18 Aug 2021
3. Kelsky K. The professor is in: the essential guide to turning your Ph.D. into a job. Crown; 2015.

4. Fernandes JD, Sarabipour S, Smith CT, Niemi NM, Jadavji NM, Kozik AJ, et al. Research culture: a survey-based analysis of the academic job market. Elife. 2020;9:e54097.

5. Heller R. A cost-benefit analysis of face-to-face and virtual communication: overcoming the challenges. 2010. January 2010.

6. Kelsky K. Disappointed with the offer? The chronicle of higher education. 2015.

7. Dealing with disappointing offers. 2018. https://www.jobsforscientists.com/wpcontent/uploads/2018/10/Disappointing_Offers.pdf. Accessed 18 Aug 2021.

8. Van Bavel JJ, Lewis NA, Cunningham WA. "In the tough academic job market, two principles can help you maximize your chances." Science, 2019. https://www. science.org/content/article/tough-academic-job-market-two-principles-can-helpyou-maximize-your-chances. Accessed 18 Aug. 2021.

9. Wright $\mathrm{CB}$, Vanderford NL. What faculty hiring committees want. Nat Biotechnol. 2017;35:885-7.

10. Gibbs KD, Basson J, Xierali IM, Broniatowski DA. Decoupling of the minority Ph.D. talent pool and assistant professor hiring in medical school basic science departments in the US. Elife. 2016;5:e21393.

11. Meyers LC, Brown AM, Moneta-Koehler L, Chalkley R. Survey of checkpoints along the pathway to diverse biomedical research faculty. PLoS One. 2018;13:e0190606.

12. Diversity Matters. https://extramural-diversity.nih.gov/diversity-matters. Accessed August 2021.

\section{ACKNOWLEDGEMENTS}

We thank Drs. Denise Cai, Roger Clem, Mario Penzo, and Nancy Padilla Coreano for comments on this piece. Work is supported by K99 MH126429-01 to SB, and K99 MH122228 to KAC. The authors declare no competing interests. Disclaimer: The views expressed in this commentary do not necessarily represent the views of the National Institutes of Health, the Department of Health and Human Services, or the United States Government.

\section{AUTHOR CONTRIBUTIONS}

SB and KAC conceptualized, gathered resources, and wrote the manuscript.

\section{ADDITIONAL INFORMATION}

Correspondence and requests for materials should be addressed to Sofia Beas or Kirstie A. Cummings.

Reprints and permission information is available at http://www.nature.com/ reprints

Publisher's note Springer Nature remains neutral with regard to jurisdictional claims in published maps and institutional affiliations. 